Dom. Cien., ISSN: 2477-8818

Vol. 5, núm.1., ene, 2019, pp. 242-262

Mapa de Riesgos Penales como parte estructural o no de un Criminal Compliance en la actividad minera empresarial

\title{
Mapa de Riesgos Penales como parte estructural o no de un Criminal Compliance en la actividad minera empresarial ${ }^{1}$
}

\section{Map of Criminal Risks as a structural part or not of a Criminal Compliance in the business mining activity ${ }^{1}$}

\section{Mapa de Riscos Criminais como parte estrutural ou não de um Compliance Criminal na atividade de mineração de negocios ${ }^{1}$}

\author{
Zulay E. Coronel-Jiménez ${ }^{\mathrm{I}}$ \\ zcoronel_est@utmachala.edu.ec \\ Bolívar J. Motoche-Peñafiel II \\ bmotoche_est@utmachala.edu.ec \\ Gabriel Y. Suqui-Romero III \\ gsuqui@utmachala.edu.ec
}

Recibido: 10 de octubre de 2018 * Corregido: 30 de octubre de 2018 * Aceptado: 30 de noviembre de 2018

I. Estudiantes de la Carrera de Derecho de la Universidad Técnica de Machala, Machala, Ecuador.

II. Estudiantes de la Carrera de Derecho de la Universidad Técnica de Machala, Machala, Ecuador.

III. Doctor en Jurisprudencia y Abogado de los Tribunales de Justicia de la Republica; Master Universitario en Derecho, Orientación Investigadora Especialidad en Derecho Penal; Profesor Titular de Derecho penal y Práctica penal de la Universidad Técnica de Machala, Machala, Ecuador. 


\section{Resumen}

La actividad minera que además de compleja resulta de por sí riesgosa, constituye un importante sector productivo en la economía ecuatoriana. La Constitución de la República del Ecuador, al reconocer a la naturaleza en la que se desarrolla esta actividad, como sujeto de derechos, le otorga también un conjunto sistemático de leyes que la protegen, entre ellas, la penal. Esta actividad que puede ser desarrollada tanto por personas naturales individualizadas, como por empresas de cualquier tamaño y en pequeña, mediana o alta escala, requiere para su funcionamiento la observancia de regulaciones administrativas, que de incumplírselas pueden desembocar en sanciones penales a título de responsabilidad penal o no. En este sentido, el COIP, tipifica dos conductas delictuales propias que regulan la actividad y el financiamiento o suministro de maquinarias ilícitos para la extracción de recursos mineros, respectivamente. Por su parte, y pese a que la regulación ecuatoriana sobre la responsabilidad penal de la persona jurídica, no contempla al compliance como eximente o atenuante de esa responsabilidad, este trabajo prevé la importancia de que el sector empresarial, cuente al menos con un Mapa de Riesgos Penales, que le permita en ejercicio del correcto actuar empresarial, contar con un instrumento de detección, valoración y prevención de conductas delictivas, propias y asociadas a la actividad minera, con miras por una parte a evitar la comisión de potenciales delitos, y por otra, a ejercitar la cultura de cumplimiento de la Ley penal. Luego del análisis documental de información especializada y de la normativa ecuatoriana, ensayamos como parte del Mapa de Riesgos un catálogo de potenciales delitos propios o conexos de la actividad minera, así como las respectivas medidas preventivas a adoptare.

Palabras claves: Mapa de riesgos; criminal compliance; actividad minera. 


\begin{abstract}
The mining activity, which, besides being complex, is inherently risky, constitutes an important productive sector in the Ecuadorian economy. The Constitution of the Republic of Ecuador, by recognizing the nature in which this activity takes place, as a subject of rights, also grants it a systematic set of laws that protect it, including criminal law. This activity that can be developed both by individualized individuals, as well as by companies of any size and in small, medium or high scale, requires for its operation the observance of administrative regulations, that failure to comply with them can lead to criminal penalties as a criminal liability or not. In this sense, the COIP, typifies two own criminal conducts that regulate the activity and the financing or supply of illicit machineries for the extraction of mining resources, respectively. On the other hand, and despite the fact that the Ecuadorian regulation on the criminal liability of the legal entity does not contemplate compliance as an exemption or mitigation of this responsibility, this work foresees the importance of the business sector having at least one Map of Criminal Risks, which allows you to exercise the right business action, have an instrument for detection, assessment and prevention of criminal behavior, own and associated with mining activity, with a view to prevent the commission of potential crimes, and another, to exercise the culture of compliance with the criminal law. After the documentary analysis of specialized information and the Ecuadorian regulations, we tested as part of the Risk Map a catalog of potential own or related crimes of the mining activity, as well as the respective preventive measures to be adopted.
\end{abstract}

Key words: Map of risks; criminal compliance; mining activity. 


\section{Introducción.}

A partir del año 2014, Ecuador promulga el Código Orgánico Integral Penal (en adelante COIP), dentro del cual incorpora la responsabilidad penal de las personas jurídicas (en adelante RPPJ). Concretamente los artículos 49 y 50 del mencionado cuerpo legal, regulan en la Parte General esta institución penal que mueve y trastoca la forma de hacer empresa en Ecuador, y que ha suscitado en el quehacer empresarial ciertos temores (Suqui Romero, Ramón Merchán, \& Cando Pacheco, 2018) que merecen la atención de la sociedad ecuatoriana dado la trascendencia de la actividad empresarial en la economía del país.

La RPPJ al ser un tema de nova data en Ecuador, requiere de análisis profundos y tratamiento especializado so pena de generar incertidumbre tanto en los destinatarios de esa punición, y en los operadores encargados de su tratamiento judicial, toda vez que como su nombre lo indica, implica una responsabilidad penal con todas las consecuencias que ésta acarrea. Y precisamente por tratarse de una institución nueva, aún no existe en Ecuador, doctrina suficiente, ni jurisprudencia que explique sus alcances, por lo que este trabajo tiende a aportar, desde la especificidad del mapa de riesgo, al debate de una de las necesarias consideraciones en esa responsabilidad penal como es el criminal complicance, y en el caso concreto que nos ocupa, dentro de la actividad minera.

El criminal complience como "instrumento base” (López Cobeña, 2018) preventivo para la comisión de delitos, constituye a la vez el instrumento del que una corporación persona jurídica puede servirse para evitar o al menos atenuar su responsabilidad penal, de allí su importancia. Su estructura va a depender del tamaño de la empresa y de sus necesidades, pero en cualquier caso, el 
Mapa de Riesgos constituye uno de los instrumentos preponderantes para la consecución de sus propósitos.

Por su parte, al actividad minera ha sido desde sus inicios centro de discusiones muchas veces polémicas, pues "por un lado, están sus efectos adversos sobre el medio ambiente y el ecosistema y, por otro, los intereses económicos presentes en la explotación minera” (SuárezLópez., 2017), en una suerte de explotación para el desarrollo versus defensa de la naturaleza, se ha ceñido siempre el debate que ha dado visos de aceptación del primero con resguardo del segundo con el amparo de sanciones penales.

El Compliance. Es abundante la literatura especializada que unas veces lo define como un “...dispositivo interno que las empresas implementan para cumplir con la normatividad vigente, así como para prevenir y detectar las infracciones legales que se produzcan dentro de las mismas o como parte de las actividades que estas realizan" (Clavijo Jave, 2014, pág. 630). Por su parte, Bock (2013) respecto de su implementación, lo determina como la toma de medidas de supervisión para evitar actos delictuosos; aunque también se lo considera como "la herramienta web que identifica los riesgos asociados al incumplimiento de la normativa penal y sus procedimientos" (Kluwer, 2018). Entendido además como esfuerzos, Artaza Varela (2013), buenas prácticas Muñoz (2018), medidas de gestión Astudillo \& Jiménez (2015), o programas éticos de cumplimiento efectivo (Gómez-Jara Díez, 2010), lo que se promueve con él es fomentar la cultura de cumplimiento de la ley en el interior de una actividad empresarial a fin de luchar contra la deslealtad y promover la ética y códigos de conducta de toda la organización, de ahí que comúnmente se asocien los términos “compliance y cultura empresarial” (Reyna Alfaro, 2018). 
En cuanto a su estructura, el compliance entendido como modelo de organización, gestión y control, es elaborado a través de un conjunto de elementos que intervienen para evitar la infracción de las normas por parte de las personas que interactúan en la actividad empresarial. Para su elaboración debe pasar por etapas como la formulación, implementación, asimilación por los involucrados, consolidación, balance de su aplicación y mejoramiento de la reglamentación. (Balcarce \& Berruezo, 2016, pág. 163)

Aunque como se indicó supra, si bien es cierto que no existe un formato de modelo específico con estructura replicable en forma idéntica, en su mayoría se encuentra estructurado por seis elementos básicos que lo integran.

a) El compromiso de la alta administración, consiste de la toma de decisión que incluye el proceso de la formación de la voluntad por parte del órgano principal. Se basa en compromisos de ética y transparencia que involucra la responsabilidad desde el nivel jerárquico principal hacia toda la organización, que empezando por sus líderes, busca concientizar a todos los empleados, con miras a garantizar el cumplimiento de todo el equipo de trabajo inclusive de aquellos que no siendo parte directa de la empresa, tienen algún tipo de relación con ella, generando la cultura organizacional basada en responsabilidades y acciones positivas. b) El Código de ética, es el compromiso escrito de la organización por seguir procedimientos de lucha contra las malas prácticas empresariales, con carácter no impositivo o vinculante, en caso de incumplimiento la empresa se ve afectada en su reputación y por ende, supone un perjuicio "en su valoración de mercado" (Navas Mondaca, 2013). En este Código se establecen las conductas que regirán el cumplimiento de sus metas y las relaciones laborales entre el equipo de trabajo, y básicamente contendrá: Un catálogo de valores, un conjunto de derechos y deberes, previsiones, el reconocimiento de una potestad disciplinaria, 
determinación de los responsables, la creación de los canales de comunicación o denuncias, la remisión a los procedimientos futuros de cumplimiento, y procedimientos de revisión, actualización y modificación de sus contenidos (Peces Juanes \& et. al., 2017). c) Mapa de riesgos penales*. d) el canal de denuncias, conocido también como whistleblowing, son sistemas corporativos internos en los cuales "se canalizan las denuncias o quejas de empleados sobre comportamientos, acciones o hechos (...) que puedan constituir infracciones de las leyes, de la normativa interna de la compañía o de los códigos éticos que rigen su actividad diaria" (Rojas Rosco, 2017, párr. vii). e) Los sistemas de disciplinas y de incentivos, permiten actuar con carácter preventivo ante los presuntos infractores a través del control y auditoría interna permanente en todas las áreas de la organización; y, con carácter sancionador aplicando medidas correctivas y sanciones a los participantes de la violación creando un patrón de modelo de conducta, con el fin de impulsar un cambio cultural orientado a la ética y obteniendo así una imagen de transparencia empresarial. Además, se debe incorporar incentivos para que la organización coopere y sienta confianza de estar bajo programas de cumplimientos; y f) El sistema de revisión y mejora continua, corresponde al monitoreo continuo, la repetición de patrones que estén respondiendo correctamente a los objetivos y la adaptación del programa a los cambios posteriores a fin de mejorar el existente.

El Criminal Compliance, puede diferenciarse del officer complaince, por su puntualidad, es decir su especificidad radica en cuestiones netamente penales, en tal sentido Neira, lo refiere como programas de cumplimiento normativo penal (Neira Pena, 2016), a diferencia del offcier, cuyo campo de acción es mucho más amplio, donde pueden preverse riesgos laborales, administrativos, entre otros. 


\section{EI Mapa de Riesgos penales*.}

En términos generales puede ser considerado como "una herramienta de análisis esencial que, entre otros usos, permite identificar zonas de mayor o menor riesgo frente a diferentes peligros (...)" (Renda, et al., 2017). En términos más específicos, puede ser considerado como el instrumento que a través de cierta información de carácter descriptiva y de indicadores adecuados, posibilitan la valoración y el análisis periódico de los riesgos (García Gómez, 1994) de una empresa, y que como parte de un compliance, permiten y garantizan la eficiencia y eficacia en el desarrollo de los procesos a los que está destinado. Además, se establecen como requisitos de validez y su función es la de analizar, evaluar el riesgo de comisión de delitos y a través de los mecanismos y procesos reducir las posibles infracciones que conlleven a la RRPJ. Su elaboración, diseño y estructura dependen de la actividad empresarial en la que se lo va implementar, no obstante, para sus propósitos debe contener lo siguiente:

Un Catálogo de delitos, que deberá ser desarrollado por expertos en Derecho penal, bajo un cuidadoso análisis que identifique todos los posibles delitos que puedan producirse en distintas áreas dentro de la actividad empresarial. Este catálogo se elabora a partir de la identificación de los riesgos penales, tomando en consideración por una parte, el tamaño de la empresa, y, por otro, el sector de actividad, dos aspectos importantes a partir de los cuales los expertos penalistas procederán a la identificación y consecuente catalogación de infracciones.

El nivel de probabilidad de riesgo y de impacto. Sirve para priorizar los riesgos y darle un orden de mayor a menor, calificados en tres niveles que son alto, medio y bajo. Se deberá incluso determinar la prioridad de probabilidad de riesgo e impacto detectados, que serán los factores relevantes para establecer los controles de acción y/o corrección en cada departamento donde se 
origina. En este nivel se ha tomar en consideración los criterios de valoración o evaluación del riesgo, los que dependerán, entre otros, de factores como el impacto económico negativo versus el positivo que generen por una parte, la comisión de delitos por su no detección y prevención; y, por otra el costo de su implementación. En conjunto a de sopesarse el coste resultado de la inversión, versus el coste estimable de pérdidas y gastos que se puedan producir en caso de verse involucrada en la comisión de delitos, y el resultado obviamente que deberá ser siempre positivo. Otro de los factores son los rangos advertidos supra, y el área de la empresa que obedecerá a la actividad o sector a la que se dedique, por ejemplo, en caso de una empresa dedicada a la actividad minera, bien podría considerarse, el área de producción, administración, contabilidad, comercialización, legal, recursos humanos, y los órganos de la propia empresa como la junta general y el de administración (Hidalgo-Barquero Jimménez, 2016).

Las medidas de prevención. Son correctivos o actuaciones empresariales que se adoptan para prevenir cada uno de los potenciales delitos detectados en el catálogo. Esas medidas de prevención no son antojadizas, ya que influirán directamente en $<<l a$ salud reputacional $>>$ de la empresa. De ahí que se afirme que el daño reputacional constituye uno de los factores que también deberán tomarse en consideración. Y, precisamente:

Con este fin, las compañias deben cimentar un modelo eficiente de Prevención de los Riesgos que afectan a la reputación, alrededor del levantamiento de sus respectivos mapas de riesgos, que facilite el acercamiento sistemático a la revisión crítica de todos los procesos y procedimientos susceptibles de sufrir contingencias que puedan derivar en futuras situaciones de crisis con daño potencial a la reputación (Segarra, García, \& Pellicer, 2016). 
Aunque la reputación empresarial sea una previsión necesaria de las acciones a tomarse como medidas preventivas, deben tomare sobre la base de ese norte ético y filosófico del que hacer empresarial, su cultura de cumplimiento como parte de ese Buen Gobierno Corporativo, luego:

En este contexto las empresas deben establecer los mecanismos que les permitan identificar las indeterminaciones que afectan a sus diferentes actividades y procesos, analizar los controles existentes para minorar la posibilidad de que un riesgo potencial se materialice en una pérdida cierta, y adoptar medidas para reducir o controlar el riesgo en aquellas áreas donde se observe que está por encima de los límites tolerables para la empresa (Rodríguez López, Piñeiro Sánchez, \& De LLano Monelo, 2013).

Esto documento, como parte del Mapa de Riesgos, debe constituirse en el marco adecuado para la posterior definición, revisión y para la consecución de los reales objetivos del compliance penal, pero también para sus propios propósitos de contribuir al ejercicio de la cultura de cumplimiento en caso de que se lo implemente asilado de aquél (Peces Juanes \& et. al., pág. 55).

\section{Delitos contra la actividad minera.}

Siendo la actividad minera compleja y de por sí riesgosa, pese a que se la conciba como el "Arte de laborear o explotar las minas" (Cabanellas, 1972, pág. 709), se debe tener especial cuidado a la hora de practicarla. Esta actividad desarrollada también y en gran medida, por empresas mineras que realizan desde minería artesanal hasta la de gran escala con un porcentaje estadístico de alrededor del 14\% que equivale al 3,7 millones de hectáreas del territorio nacional (Zorrilla, 2018). Estas actividades mineras empresariales centran, sobre todo, sus esfuerzos sus recursos como el oro, 
plata y cobre, y además de una oferta variada de otros tipos de minerales, convirtiéndose en un sector de gran importancia para la economía ecuatoriana.

Dado precisamente, a que, como se advirtió supra, el riesgo que implica la actividad minera, además de las exigencias de índole administrativas que contempla la legislación ecuatoriana para su regulación, el legislador la precautela con fines punitivos su ilicitud en el COIP. En tal sentido, el art. 260 que sanciona la actividad ilícita de recursos mineros, señala que:

La persona que sin autorización de la autoridad competente, extraiga, explote, explore, aproveche, transforme, transporte, comercialice o almacene recursos mineros, será sancionada con pena privativa de libertad de cinco a siete años. En caso de minería artesanal será sancionada con pena privativa de libertad de uno a tres años. Si producto de este ilícito se ocasionan daños al ambiente, será sancionada con pena privativa de libertad de siete a diez años.

Pero no solamente se sanciona la actividad minera ilícita sino también su financiamiento o el suministro de maquinarias que faciliten la extracción ilegal de los recursos mineros. Así el art. 261 del COIP, señala que:

La persona que, en beneficio propio o de terceros, financie o suministre a cualquier título, maquinaria, equipos, herramientas y en general cualquier instrumento que se utilice para realizar las actividades ilícitas descritas en el artículo anterior, será sancionada con pena privativa de libertad de tres a cinco años.

Esta regulación a decir de Bramont-Arias y García (2006) que protege al medio ambiente, se justifica frente a los nuevos ataques lesivos a esta clase de bienes jurídicos, en donde el Derecho 
penal es el medio idóneo para reducirlos o neutralizarlos. Luego el Derecho penal ecuatoriano, al incorporar a través de los arts. 49 y 50 del COIP la RPPJ, precautela la actividad minera no solamente de las personas naturales sino también de las empresas o personas jurídicas de derecho privado. En este sentido, para esta clase de delitos, en caso de ser cometidos por una empresa privada, el art. 267 determina la sanción a la persona jurídica con multa de quinientos a mil salarios básicos unificados del trabajador en general.

No obstante de la protección penal indicada, dado la advertencia de riesgos que conlleva la actividad minera, se pueden detectar otros potenciales delitos en los que una empresa que se dedica a esta clase de actividad puede verse involucrada, como la corrupción con la administración, defraudación tributaria, trabajos forzosos, entre otros que deben ser advertidos en el Mapa.

\section{Metodología.}

La presente investigación se ha realizado mediante una revisión documental y bibliográfica de tipo no experimental. La información recabada y los análisis realizados de los mismos, fueron mediante medios electrónicos, en donde hay información relevante sobre los riesgos de la actividad minera empresarial y afines.

\section{Discusión.}

En la extracción de oro, por ejemplo, que es la principal actividad minera artesanal, el "mapa de riesgos identifica en que pasos del proceso productivo minero artesanal de oro se presenta la probabilidad de contaminación por la manipulación del cianuro" (Geco).

Sea que se lo elabore como parte estructural de un compliance o fuera de él en ejercicio de políticas de transparencia y correcto funcionamiento empresarial, el mapa de riesgos penales de una 
actividad minera, debe estructurarse en al menos tres niveles de impacto, correspondiendo a 1 el nivel bajo, 2 el nivel medio, 3 el nivel alto.

Dado que la naturaleza de la actividad minera además de ser compleja, de por sí es riesgosa, cobra trascendente importancia el mapa de riesgos penales, el que no solo debe constituir una necesidad ética en aras a observar el cumplimiento de la legalidad, sino que, además, una exigencia normativa. De ahí cobra importancia su empleo en el ámbito del Derecho penal, el que en caso de habérsele observado y aplicado independientemente o dentro de un officer complienace o criminal compliance, beneficiará a las empresas de cara a enfrentar esa responsabilidad penal, si dentro de un compliance que funciona en forma coadyuvará a que se exima de responsabilidad penal a la empresa, o si es fuera de un compliance, servirá al menos para atenuar esa responsabilidad. Esto amén de que el COIP no lo prevea como causa de exclusión ni atenuante de responsabilidad penal, sin embargo, bien podría ser alegado en seno probatorio.

Lo advertido no equivale a que una empresa del sector minero en cumplimiento de políticas, regulaciones y exigencias institucionales tenga que incorporar mapas de riesgos de su rama de actividad y por ende ya no necesite otro. El mapa de riesgos penales no resulta incompatible con ningún otro, en el sentido, precisamente, que en él se prevén y evalúan riesgos de naturaleza penal, es decir, la posible comisión de delitos, y al contrario, siempre será compatible con cualquier otro, inclusive, bien podría formar parte de un mapa general de riesgos, que por lo general, siempre prevén riesgos administrativos, ambientales y laborales. Es decir, una empresa minera bien podría adoptarlo de forma independiente, dentro de otros mapas como parte estructural de un officer compliance, o al menos dentro de un específico criminal compliance. No obstante, solamente formando parte de los dos segundos, están encaminados a librarlos de posible responsabilidad penal, 
en la medida que sean eficientes y eficaces; mientras que en el primer caso, servirá al menos para atenuar la responsabilidad penal. En otras palabras, se puede afirmar que el mapa de riesgos penales dentro de los (...) compliance, se dirige a proteger a las personas jurídicas del riesgo de incurrir en responsabilidad penal, con todos los costes que esto conlleva (...) (Santelices I, 2016), sobre todo en empresas que dirigen su actividad a un sector sensible como el minero.

Además de las cuestiones anotadas supra para la estructuración de un mapa de riesgos penales, en la actividad minera requiere que se tome en consideración estimaciones como: el escenario de los riesgos, la estimación de del índice de probabilidad de ocurrencia, y la severidad de las consecuencias (Motta-Pascuas, Ustariz-Durán, \& Ordoñez-Carmona, 2018).

\section{Conclusiones.}

El legislador ecuatoriano no ha dicho nada al respecto de los compliance, como sucede por ejemplo, con efectos impositivos en EEUU., en donde se contempla vía condena, su obligatoriedad en casos de delitos contra el medio ambiente (Villegas García, 2016), sin embargo, su implementación es necesaria como “instrumento útil” (Marqués Racionero, Marín Fábregas, \& Molina Conde, 2012), en aras a ejercitar la cultura de cumplimiento empresarial y como parte de esas "políticas anticorrupción en la empresa" (García Cavero, 2016). Los compliance deben ser efectivos e idóneos para fomentar el cumplimiento de la ley, prevenir y detectar las conductas ilícitas cuyas normas, procedimientos y mecanismos de estructuración deben promover la cultura organizacional basada en la ética, aspectos que pueden advertirse también en los Lineamientos de la United States Sentencing Commission (2016) que han sido adoptados e implementados en algunos países como Chile, Brasil, Argentina y EEUU. 
Por su parte, sea que se lo estructure dentro de un compliance o fuera de él, el Mapa de Riesgos, constituye la herramienta preponderante para la detención y prevención de delitos, ya que se ha de elaborar tomando en consideración factores como el impacto económico, y área de cada actividad según el sector al que se dedique a empresa, que en el caso de una empresa del sector minero puede ser entre otras el área de producción, de comercialización, legal, recursos humanos, contable, y los órganos de la propia empresa.

En lo particular, dado lo sensible de la actividad minera, resulta preponderante que las empresas que se dedican a ella, cuenten al menos con un Mapa de Riesgos que permita prevenir la comisión de delitos, mantener la salud reputacional de la empresa, sobre todo en esta actividad que reviste especial cuidado y atención. En tanto que, en lo general, la importancia de su conocimiento se encamina a la mitigación de los efectos penales en tiempos de responsabilidad penal de las personas jurídicas, así como de la necesidad de implementarlos como parte de los compliance, con miras a fomentar la cultura de cumplimiento y por ende a ejercitar el Buen Gobierno corporativo.

\section{Bibliografía.}

Artaza Varela, O. (2013). Sistemas de prevención de delitos o programas de cumplimiento. Breve descripción de las reglas técnicas de gestión del riesgo empresarial y su utilidad en sede jurídico penal. Scielo, 8(16), 544-573. Recuperado el 17 de 09 de 2018, de https://scielo.conicyt.cl/pdf/politcrim/v8n16/art06.pdf

Astudillo Meza, G., \& Jiménez Montes, S. (Octubre de 2015). Programas de Cumplimiento Como Mecanismo de Lucha Contra la Corrupción: Especial Referencia a La Autorregulación de Las Empresas. Derecho \& Sociedades(45), 63-73. Recuperado el 14 de 09 de 2018, de http://revistas.pucp.edu.pe/index.php/derechoysociedad/article/view/15225/15693

Balcarce, F. I., \& Berruezo, R. (2016). Criminal Compliance y Personas Jurídicas. (J. C. Faira, Ed.) Montevideo, Uruguay: B de F Ltda. Recuperado el 04 de Noviembre de 2018

Bock, D. (2013). Compliance y deberes de vigilancia en la empresa. En L. Kuhlen, J. P. Montiel, \& Í. Ortiz de Urbina Gimeno, Compliance y Teoría del Derecho Penal (pág. 300). Madrid, 
España: Marcial Pons. Recuperado el 2 de Noviembre de 2018, de https://www.marcialpons.es/media/pdf/9788415948001.pdf

Bramont-Arias Torres, L., \& Garcia Cantizano, M. (2006). MANUAL DERECHO PENAL Parte Especial. San Marcos.

Cabanellas, G. (1972). Diccionario de Derecho Usual. Buenos Aires.

Clavijo Jave, C. (2014). Criminal compliance en el derecho penal peruano. Derecho PUCP(73), 625-647. Recuperado el 04 de Noviembre de 2018, de http://revistas.pucp.edu.pe/index.php/derechopucp/article/view/11321/11830

FULLSIX. (29 de Enero de 2013). MODELLO DI ORGANIZZAZIONE, GESTIONE E CONTROLLO. Italia. Recuperado el 17 de 09 de 2018, de https://www.fullsix.it/wpcontent/uploads/2013/09/v04_modello_organizzativo_parte_generale_draft_01_.pdf

García Cavero, P. (2016). Las políticas anticorrupción en la empresa. Revista de Derecho de la Pontificia Universidad Católica de Valpaíso, 219-244.

García Gómez, M. (1994). Los mapas de riesgos. Concepto y metodología para. San Ignacio, 443453.

Geco, M. A. (s.f.). Mapa de Riesgos -Geco-Minero Aretesanal. Recuperado el 21 de Enero de 2019, de http://geco.mineroartesanal.com/tiki-download_wiki_attachment.php?attId=457.

Gómez-Jara Díez, C. (2010). La resposanbildiad penal de las personas juridicas en Estados Unidos de Norte América. Lima: Ara Editores.

Hidalgo-Barquero Jimménez, F. J. (26 de febrero de 2016). Legal y Fiscal Grupo SCA. Obtenido de https://legal.gruposca.com/compliance-como-elaborar-un-mapa-de-riesgos/

Kluwer, W. (2018). Complylaw. Madrid, España. Recuperado el 14 de 09 de 2018, de Wolters Kluwer: https://www.wolterskluwer.es/productos/herramientas-de-gestion/complylaw.html

López Cobeña, A. (2018). La resposanbilidad penal de las personas jurídicas. El nuevo paradigma de la legislación ecuatoriana en el COIP. Quito: Cevallos.

Marqués Racionero, M. J., Marín Fábregas, V., \& Molina Conde, M. L. (2012). Guía de elaboración de mapa de riesgo. Enfermería Neurológica, 176-177. Recuperado el 13 de enero de 2019, de http://scielo.isciii.es/scielo.php?script=sci_arttext\&pid=S225428842012000500115\&lng=es\&tlng=es.

Motta-Pascuas, A., Ustariz-Durán, M., \& Ordoñez-Carmona, O. (2018). Identificación, análisis y evaluación de riesgos asociados a la actividad minera de oro en el Municipio de Marmato, Caldas. Boletín de Ciencias de la Tierra, 21-30. doi:https://doi.org/10.15446/rbct.n43.61646 
Muñoz, M. (08 de Junio de 2018). Compliance o programas de cumplimiento normativo: ¿cuáles son los requisitos mínimos que han de reunir? Madrid, España. Recuperado el 14 de 09 de 2018, de http://www.hispajuris.es/blog/circulares/compliance-o-programas-decumplimiento-normativo-cuales-son-los-requisitos-minimos-que-han-de-reunir/

Navas Mondaca, I. (2013). Los Códigos de Conducta y el Derecho penal económico. En S. S.-M. (Dir.), \& M. F. (Coord.), Criminalidad de empresa y Compliance. Prevención y reacciones corporativas. (págs. 111-129). Barcelona: Atelier.

Neira Pena, A. M. (2016). La efectividad de los criminal compliance programs como objeto de prueba en el proceso penal. Política Criminal, 467-520. Obtenido de http://www.politicacriminal.c1/Vol_11/n_22/Vol11N22A5.pdf

Peces Juanes, Á., \& et. al. (2017). Compliance penal. Madrid: Francis Lefebvre.

Renda, et al., E. (2017). Manual para la elaboración de mapas de riesgos. Buenos Aires: PNUD.

Reyna Alfaro, L. (2018). Implementación de los Compliance Programs y sus efectos de exclusión o atenuación de respsoanbilidad penal de los sujetos obligados. En I. C. Luis Miguel Reyna Alfaro (Dir.), Compliance y responsabilidad penal de las personas jurídicas. Perspectivas comparadas (EE.UU., España, Italia, México, Argentina, Colombia, Perú y Ecuador. (págs. 206-247). Lima: Ideas Soluciones S.A.C.

Rodríguez López, M., Piñeiro Sánchez, C., \& De LLano Monelo, P. (2013). Mapa de Riesgos: Identificación y Gestión. Revista Atáltica de Economía, 1-29. Recuperado el 21 de Enero de 2019 , http://www.unagaliciamoderna.com/Eawp/coldata/upload/mapa_de_riesgos_19_06_13.pdf

Rojas Rosco, R. (02 de Febrero de 2017). Los canales de denuncia interna (whistleblowing) en el ámbito laboral. COMPLIANCE LABORAL. Recuperado el 24 de 09 de 2018, de https://elderecho.com/los-canales-de-denuncia-interna-whistleblowing-en-el-ambito-laboral

Santelices I, W. (2016). La responsabilidad penal de las personas jurídicas: Modelos de autorresponsabildiad. Novedades Jurídicas, 6-19.

Segarra, J. A., García, D., \& Pellicer, C. (2016). Compromiso empresarial. Obtenido de Gestión preventiva de la reputación corporativa: el mapa de riesgos: https://www.compromisoempresarial.com/rsc/2006/06/gestion-preventiva-de-la-reputacioncorporativa-el-mapa-de-riesgos/

Suárez-López., B. E. (2017). RETOS DE LA REGULACIÓN JURÍDICO-PENAL DE LA MINERÍA EN COLOMBIA. ESTUDIO DEL ARTÍCULO 333 DEL CÓDIGO PENAL COLOMBIANO. Universitas, 421-456. 
Suqui Romero, G., Ramón Merchán, M., \& Cando Pacheco, J. (2018). Temores empresariales en tiempos de resposanbildiad penal de las personas jurídicas. Universidad y Sociedad, 89-95.

UNITED STATES SENTENCING COMMISSION. (01 de Noviembre de 2016). GUIDELINES MANUAL 2016. EEUU. Obtenido de https://www.ussc.gov/sites/default/files/pdf/guidelinesmanual/2016/GLMFull.pdf

Villegas García, M. Á. (2016). La responsabilidad criminal de las personas jurídicas. La experiencia de Estados Unidos. . Cizur Menor: Aranzadi, SA.

Zorrilla, C. (09 de Enero de 2018). La Línea de Fuego. Ecuador. Recuperado el 04 de Noviembre de 2018, de https://wp.me/pW6em-4A3 
Dom. Cien., ISSN: 2477-8818

Vol. 5, núm.1. ene., 2019, pp. 242-262

\section{ANEXOS:}

\begin{tabular}{|c|c|c|c|c|}
\hline \# & Artículo & Supuesto de Hecho & Probabilidad & Impacto \\
\hline 1 & 105 & Trabajos forzados u otras formas de explotación laboral. & Poco Probable & Alto \\
\hline 2 & 201 & Ocupación, uso ilegal de suelo o tráfico de tierras. & Poco probable & Medio \\
\hline 3 & 204 & Daño a bien ajeno & Poco Probable & Bajo \\
\hline 4 & 205 & Insolvencia fraudulenta. & Probable & Medio \\
\hline 5 & 235 & $\begin{array}{l}\text { Engaño al comprador respecto a la identidad o calidad de } \\
\text { las cosas o servicios vendidos. }\end{array}$ & Poco Probable & Bajo \\
\hline 6 & 242 & Retención ilegal de aportación a la seguridad social. & Probable & Medio \\
\hline 7 & 243 & $\begin{array}{l}\text { Falta de afiliación al Instituto Ecuatoriano de Seguridad } \\
\text { Social. }\end{array}$ & Probable & Bajo \\
\hline 8 & 245 & Invasión de áreas de importancia ecológica. & Muy probable & Medio \\
\hline 9 & 246 & Incendios forestales y de vegetación. & Muy probable & Alto \\
\hline 10 & 247 & Delitos contra la flora y fauna silvestres. & Muy probable & Alto \\
\hline 11 & 251 & Delitos contra el agua. & Muy probable & Alto \\
\hline 12 & 252 & Delitos contra suelo & Muy probable & Alto \\
\hline 13 & 253 & Contaminación del aire. & Muy probable & Alto \\
\hline 14 & 254 & $\begin{array}{l}\text { Gestión prohibida o no autorizada de productos, residuos, } \\
\text { desechos o sustancias peligrosas. }\end{array}$ & $\begin{array}{l}\text { Poco } \\
\text { Probable }\end{array}$ & Medio \\
\hline 15 & 255 & Falsedad u ocultamiento de información ambiental. & Muy probable & Medio \\
\hline 16 & 260 & Actividad ilícita de recursos mineros & Muy probable & Alto \\
\hline 17 & 280 & Cohecho & $\begin{array}{c}\text { Poco } \\
\text { Probable }\end{array}$ & Medio \\
\hline 18 & 298 & Defraudación tributaria. & Probable & Alto \\
\hline 19 & 320 & Simulación de exportaciones o importaciones. & Probable & Bajo \\
\hline 20 & 328 & Falsificación y uso de documento falso. & $\begin{array}{l}\text { Poco } \\
\text { Probable }\end{array}$ & Bajo \\
\hline
\end{tabular}


Dom. Cien., ISSN: 2477-8818

Vol. 5, núm.1. ene., 2019, pp. 242-262

Mapa de Riesgos Penales como parte estructural o no de un Criminal Compliance en la actividad minera empresarial

\begin{tabular}{|c|c|c|}
\hline \# & Artículo & Medidas Preventivas \\
\hline 1 & 105 & $\begin{array}{l}\text { - Cumplimiento de normativa manual de contratación de trabajadores } \\
\text { - Cumplimiento de Reglamento Interno de Trabajo } \\
\text { - Políticas de controles permanentes en los distintos departamentos y } \\
\text { lugares de trabajo. }\end{array}$ \\
\hline 2 & 201 & $\begin{array}{l}\text { - Cumplimiento de las ordenanzas municipales y gubernamentales } \\
\text { observadas en el proceso de constitución y operaciones de la empresa. }\end{array}$ \\
\hline 3 & 204 & - Cumplimiento del Código Ético \\
\hline 4 & 205 & $\begin{array}{l}\text { - Observa Código Ético } \\
\text { - Cumplimiento de los documentos resultantes de auditorías y sus } \\
\text { protocolos. } \\
\text { - Observancia adecuada de los procesos contables }\end{array}$ \\
\hline 5 & 235 & $\begin{array}{l}\text { - Observancia y fiel cumplimiento del Código Ético propuesto a la } \\
\text { empresa } \\
\text { - Observar los manuales de derecho de los consumidores y gestión de } \\
\text { calidad del producto }\end{array}$ \\
\hline 6 & 242 & $\begin{array}{l}\text { - Cumplimiento del Reglamento Interno de Trabajo } \\
\text { - Observancia a las leyes de seguridad social }\end{array}$ \\
\hline 7 & 243 & $\begin{array}{l}\text { - Cumplimiento del Reglamento Interno de Trabajo } \\
\text { - Observancia a las leyes de seguridad social }\end{array}$ \\
\hline 8 & 245 & $\begin{array}{l}\text { - Cumplimiento de los permisos de aprobación y licencias } \\
\text { medioambientales } \\
\text { - Cumplimiento de las ordenanzas municipales y gubernamentales } \\
\text { observadas en el proceso de constitución y operaciones de la empresa }\end{array}$ \\
\hline 9 & 246 & $\begin{array}{l}\text { - Cumplimiento de los permisos de aprobación y licencias } \\
\text { medioambientales } \\
\text { - Cumplimiento de las ordenanzas municipales y gubernamentales } \\
\text { observadas en el proceso de constitución y operaciones de la empresa }\end{array}$ \\
\hline 10 & 247 & $\begin{array}{l}\text { - Cumplimiento de los permisos de aprobación y licencias } \\
\text { medioambientales } \\
\text { - Cumplimiento de las ordenanzas municipales y gubernamentales } \\
\text { observadas en el proceso de constitución y operaciones de la empresa. }\end{array}$ \\
\hline 11 & 251 & $\begin{array}{l}\text { - Cumplimiento de los permisos de aprobación y licencias } \\
\text { medioambientales } \\
\text { - Cumplimiento de las ordenanzas municipales y gubernamentales } \\
\text { observadas en el proceso de constitución y operaciones de la empresa }\end{array}$ \\
\hline 12 & 252 & $\begin{array}{l}\text { - Cumplimiento de los permisos de aprobación y licencias } \\
\text { medioambientales } \\
\text { - Cumplimiento de las ordenanzas municipales y gubernamentales } \\
\text { observadas en el proceso de constitución y operaciones de la empresa }\end{array}$ \\
\hline 13 & 253 & $\begin{array}{l}\text { - Cumplimiento de los permisos de aprobación y licencias } \\
\text { medioambientales } \\
\text { - Cumplimiento de las ordenanzas municipales y gubernamentales } \\
\text { observadas en el proceso de constitución y operaciones de la empresa }\end{array}$ \\
\hline 14 & 254 & $\begin{array}{l}\text { - Cumplimiento de los permisos de aprobación y licencias } \\
\text { medioambientales } \\
\text { - Cumplimiento de las ordenanzas municipales y gubernamentales } \\
\text { observadas en el proceso de constitución y operaciones de la empresa }\end{array}$ \\
\hline
\end{tabular}




\begin{tabular}{|c|c|c|}
\hline 15 & 255 & $\begin{array}{l}\text { - Cumplimiento de los permisos de aprobación y licencias } \\
\text { medioambientales } \\
\text { - Cumplimiento de las ordenanzas municipales y gubernamentales } \\
\text { observadas en el proceso de constitución y operaciones de la empresa } \\
\text { - Observancia y cumplimiento del Código Ético propuesto para la } \\
\text { empresa. }\end{array}$ \\
\hline 16 & 260 & $\begin{array}{l}\text { - Cumplimiento de los permisos de aprobación y licencias } \\
\text { medioambientales }\end{array}$ \\
\hline 17 & 280 & $\begin{array}{l}\text { - Observancia y cumplimiento del Código Ético propuesto para la } \\
\text { empresa }\end{array}$ \\
\hline 18 & 298 & $\begin{array}{l}\text { - Observa Código Ético } \\
\text { - Cumplimiento de los documentos resultantes de auditorías y sus } \\
\text { protocolos. } \\
\text { - Observancia adecuada de los procesos contables }\end{array}$ \\
\hline 19 & 320 & $\begin{array}{l}\text { - Observancia y cumplimiento del Código de Ética propuesto para la } \\
\text { empresa } \\
\text { - Observar el manual de buenas prácticas comerciales y el Código de } \\
\text { Comercio }\end{array}$ \\
\hline 20 & 328 & $\begin{array}{l}\text { - Observancia y cumplimiento del Código de Ética propuesto para la } \\
\text { empresa } \\
\text { - Observancia adecuada de los procesos contables. } \\
\text { - Gestión de revisiones periódicas de documentación (resultante de } \\
\text { auditorías) }\end{array}$ \\
\hline
\end{tabular}

